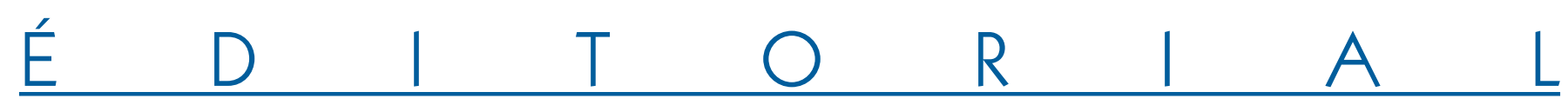

\title{
Le CECSMO est mort, vive le DES ${ }^{1} d^{\prime} O D F$ !
}

a disparition du CECSMO ne se fait pas sans nostalgie! En 35 ans de bons et loyaux services il aura perL mis la formation d'environ 2000 praticiens et sa création aura largement participé au développement de la spécialité. La mise en place de l'internat, en modifiant profondément la formation des spécialistes en ODF devrait, à son tour, dynamiser la spécialité comme l'avait fait, en son temps, le CECSMO.

En 2011, après une longue période de gestation, l'internat généraliste créé en 1995 est remplacé par un internat qualifiant, lequel conduit à la délivrance de 3 diplômes d'études spécialisées :

- diplôme d'études spécialisées de chirurgie orale, formation commune à la médecine et à l'odontologie ;

- diplôme d'études spécialisées de médecine bucco-dentaire;

- diplôme d'études spécialisées d'orthopédie dento-faciale.

Ces trois filières sont accessibles aux étudiants de D3 et T1 (5e et 6e année) par un concours national classant dans le cadre du troisième cycle long des études odontologiques.

Pour l'année universitaire 2011-2012, la spécialité d'Orthopédie Dento-Faciale est alors accessible par 2 voies, le CECSMO et le DES1 d'ODF, situation posant de nombreux problèmes. Des problèmes réglementaires, comme l'absence de statut hospitalier pour les Cecsmistes, la cohabitation de deux formations de nature très différente et pourtant menant à la même qualification. Mais aussi des problèmes d'orsanisation en rapport avec les modes d'enseignement et d'encadrement clinique (temps plein 3 ans pour l'internat et temps partiel 4 ans pour le (ECSMO).

Il devenait inéluctable que le CECSMO disparaisse, sans que l'on sache exactement à quel moment et dans quelles conditions.

Le 24 février 2012, une note du Ministère de l'Enseignement Supérieur et de la Recherche adressée aux Présidents des Universités, aux Recteurs d'Académie et aux Directeurs d'UFR d'Odontologie, annonce que les habilitations à délivrer le CECSMO arrivent à leur terme en 2012 et que dans un souci de cohérence pédagogique, elles ne seront pas renouvelées afin de conserver une seule voie pour accéder à la spécialité ODF, celle de l'internat avec le DES d'ODF. Le CECSMO était définitivement mort ! Cette même note précisait que le nombre de postes d'internes dans la filière ODF serait augmenté pour former un nombre suffisant de spécialistes. Ce nombre a été précisé par la suite : 65 postes, dont 6 à titre européen, seront ouverts au recrutement pour l'ODF dès 2012, ce qui correspond à peu près au nombre de Cecsmistes formés par an.

1 Diplôme d'Études Spécialisées. 
Cette décision, souhaitée et attendue par la majorité de la profession et du corps enseignant, a cependant surpris par sa soudaineté. De plus, l'absence regrettable de toutes mesures transitoires a plongé les candidats se préparant à passer l'examen probatoire du CECSMO en 2012 dans une situation inextricable, les privant de tout accès à la spécialité.

À partir de 2012 la seule voie menant à la spécialité est donc l'internat, les Commissions Nationales de Qualifications organisées par le Conseil National de l'Ordre devant rester une voie exceptionnelle.

L'internat est accessible aux étudiants de D3 et aux étudiants de T1 après concours. C'est en fonction du rang de classement au concours national d'internat en Odontologie que se fait le choix de la spécialité ('ODF est la première spécialité choisie !) puis le choix du lieu d'affectation. La formation se réalise sur trois ans, période pendant laquelle l'interne est à la fois étudiant en formation et hospitalier à plein temps avec statut et rémunération. Les obligations de services des internes sont fixées à onze demi-journées par semaine, comprenant deux demi-journées universitaires et neuf demi-journées hospitalières. L'activité hospitalière s'effectue dans les services agréés par les ARS² comme lieu de stage. Essentiellement composée de cliniques orthodontiques (minimum 6 demi-journées par semaine) l'activité hospitalière de l'interne comprend également des vacations en Chirurgie Orale, Chirurgie Maxillo-Faciale, Pédodontie, Occlusodontie et une participation aux Urgences Odontologiques. Des stages en pratique privée auprès d'un praticien agréé maître de stage par les ARS pourraient également être envisagés.

Afin de permettre aux praticiens en exercice d'accéder à la spécialité, il a été ouvert un internat en Odontologie dit à titre européen réservé aux praticiens des États de l'Union Européenne (dont les praticiens français), justifiant d'au moins 3 années d'exercice professionnel. Le concours est le même que celui de l'internat national mais le classement se fait sur une liste distincte. La formation est ensuite identique.

La voie de l'internat ouvre une nouvelle ère pleine de promesses permettant à notre spécialité de rappeler son appartenance à l'odontologie et d'affirmer son ancrage médical par son mode de formation en milieu hospitalier à temps plein. II est de l'intérêt de tous d'apporter son soutien à cette nouvelle voie de formation en orthodontie.

La grande majorité des enseignants croit à la formation par l'internat et s'investit totalement dans ce projet, et ce malgré l'importante remise à plat nécessaire de l'enseignement et surtout de la pédagogie. Ce travail se trouve compliqué par le départ de nombre d'entre eux au cours de ces années et leur non remplacement du fait de modifications de recrutement, mais ceci est une autre histoire...

Claude CHABRE

Président du Collège des enseignants en ODF, Coordonnateur île-de-France DES d'ODF.

Les opinions émises n'engagent que leurs auteurs.

2 Agence Régionale de Santé. 